and again tried, and proved a failure. Experience teaches us that penalties, instead of deterring a man from exposing himself to the chance of infection, only aggravate the worst consequences of the disease in the individual, cause invaliding in the service, and thereby injure society. In attempting to legislate for the masses our feelings must not warp either our judgment or experience. Observation has taught us that if we punish the soldier when suffering from the various forms of contagious diseases, he will conceal his complaint. Instead of at once applying to the surgeon of the regiment in the early stages (which is most important in these virulent complaints), the man will, from the certainty of losing a shilling a day, and being obliged to submit to confinement in hospital (the latter he considers bad enough), have recourse to the socalled specifics recognised among soldiers, or apply to some itinerant or local quack; and, what is of still more importance to society, will, whilst the treatment is going on, not scruple to have relations with women, and probably communicate these virulent complaints. In this way I have known many of the younger men of a regiment become diseased, if one infected man has been allowed to be at large and intimate with a female who is a public favourite. The object of the introduction of the Contagious Diseases Act has been, not as our opponents assert-the providing of clean women for immoral men,- but to enable us to discover and treat incipient disease in women, sending them at once into hospital, and thus preventing their contaminating healthy men. If Mr. Cardwell should not modify this measure, he will nullify our latest advance in military hygiene. Punishment is not what we require; we should attempt to keep our soldiers as free from disease as possible during the first probationary period after joining the army, and the State will thereby benefit in possessing men of a sound constitution. I trust my professional brethren, particularly those in the army, will urge Mr. Cardwell to withdraw this proposed obnoxious regulation. Let us induce the man to be cured of syphilis as soon as it shows itself; let us further, by all legitimate means, prevent this virulent complaint extending to the wife, and through her to the child. Those who have advocated the Contagious Diseases Acts have had these views at heart; and if $I$ again urge upon those in authority to continue to pay a man a shilling a day, notwithstanding he has morally forfeited it, we shall, I think, avoid a retrograde step, and this letter will not have been written in vain.

I am, Sir, yours obediently,

Queen Anne-street, March, 1873.

W. ACTON.

\section{ON FEHLING'S TEST, AND THE SIGNIFICANCE OF SUGAR IN THE URINE.}

To the Editor of THE LANCET.

SIR,-Sugar is supposed to exist in urine that decomposes Fehling's solution, and the patient passing such urine is too commonly regarded as a diabetic, and declined by insurance companies.

Now, Dr. Seegen, at the beginning of 1872 , in one of the Vienna weekly journals, proved that urea, uric acid, and urates in excess, will decompose Fehling's fluid, and give all the appearances that are usually attributed to sugar; it follows, therefore, that although the decomposition is a fact worthy of the physician's most serious attention, yet it is by no means a certain sign of the presence either of sugar or of diabetes (our only reliable test for sugar, I believe, is fermentation). But let us assume that in a given specimen of urine we do find sugar, and in quantity, are we therefore justified in concluding that we have got hold of a case of diabetes? Most assuredly not, unless we find also thirst, diuresis, emaciation, and the characteristic tongue of the diabetic; if these are wanting, no amount of mere sugar can constitute the case one of diabetes; such a case, however, is often recorded as one of diabetes cured, whereas it is not diabetes at all, but mere glycosuria. A gentleman under my care last year, whilst passing sugar to the extent of twenty-one grains per fluid ounce-as I ascertained for myself by careful analysis-looked fresh-coloured and well, kept up his flesh, had no thirst, no diuresis, nor the peculiar glazed and furrowed tongue of the diabetic. He recovered in time, as all such patients do, and all trace of sugar disappeared.

In every case, therefore, in which Fehling's fluid is decomposed, we must ascertain whether this is due to sugar, or to urea and urates; and if to sugar, whether we have before us a case of diabetes, or of mere glycosuria. This is most important in the examination of proposers for life assurance, many of whom are daily declined simply on the ground that sugar is present in their urine. On the other hand, three of our most eminent physicians recently recom. mended for assurance, at the tabular rate, a gentleman whose urine was very decidedly saccharine; and I should have had no hesitation in recommending my patient already referred to. The fact is, too much importance has hitherto been attached to the mere presence of albumen or of sugar, per se, whereas, apart from other clinical facts and the history of the patient, it teaches us extremely little respect. ing the true nature of the case before us. We know very little, as yet, about the urine. One may say it has never been analysed. What do we mean by "extractives"? Certain constituents about which we are utterly ignorant, and which may, nevertheless, be of vital importance! We know that uric acid assumes a great variety of forms, and it may be that each has its own special and associated states of the general health, although we do not distinguish them. In short, our ignorance surpasses our knowledge of the urine in health and in disease, and a vast field for investigation lies untouched before us.

I am, Sir, yours truly,

Daniet HoOPer, B.A., M.B. Trinity-square, S.E., Feb. 11th, 1873 Physician to the Surrey Dispensary.

\section{FENESTRATED NON-ADHESIVE PLASTER FOR} SKIN-GRAFTING.

\section{To the Editor of The LANCET.}

SIR,-Having frequently experienced the want of a more suitable form of plaster than that in ordinary use for the dressing of ulcerated wounds upon whose surface pieces of healthy skin had been grafted, I was induced, after many experiments, to adopt the following simple but efficacious method of producing a plaster with the requirements I considered necessary.

An oblong or oval opening is cut in the centre of a strip of adhesive plaster, which should be of the requisite breadth and of length sufficient to reach one or two inches beyond the opposite sides of the wound for whose dressing it is intended. This opening or fenestrum is easily made by folding the strip in half, lengthways, and removing a piece from the folded extremity with a pair of scissors. Upon this strip, so fenestrated, a thin strip of gutta-percha tissue of the same breadth, but somewhat shorter, is then laid over its adhesive surface, and made to adhere by means of a little gentle pressure with the warm hand.

In placing this on care should be taken to make it lie evenly, and to extend equally on either side of the fenestrum. Being thus prepared, it is placed over the wound in such a position that the skin-graft will be directly beneath the fenestrum, and seen through it as through a window. pane.

It will be found to possess the following advantages:-

1. The gutta-percha tissue will render the surface of the plaster covered by it perfectly non-adhesive, whilst those portions uncovered at the extremities will readily adhere to the healthy skin.

2. The fenestrum over which the tissue is seen stretched will be found transparent, so that the growth and development of the graft beneath may be viewed from time to time. Although, for all practical purposes, the guttapercha tissue in ordinary use for surgical dressing will be found a sufficiently transparent medium, still where a more perfect one is required, as for clinical instruction, a thin layer of mica or talc may be substituted. This is a more ex pensive material, and of no superior advantage for general use.

3. It will be found stouter, and to retain the graft in situ better than the various transparent plasters now used. In addition to this, it is not so liable to draw into a twisted string as the latter almost invariably do. 
In conclusion, I may say that if a non-absorbent adhesive plaster could be obtained for the purpose, it would be greatly advantageous, as then it might be allowed to remain on the wound for days without becoming foul. I have not in practice seen such a plaster used, but think it might be easily made by applying the adhesive material over a waterproof fabric instead of on the ordinary calico. Not only in this, but in other departments of surgery would a nonabsorbent adhesive plaster be found nseful.

$$
\text { Yours faitbfully, }
$$

JoHN W. BuIGH, M.D. Montreal,

March 3rd, 1873. late House-Surgeon, Kidderminster Infirmary.

\section{THE LATE MR. ISAAC BAKER BROWN. \\ To the Editor of THE LANCET.}

SiR,-May I trespass once more on your kindness, and be permitted through your journal to inform the subscribers to the "Baker Brown Fund" that it is proposed that Mrs. Brown be permitted to draw from the balance of the fund ( 21717 s. 10d.) $£ 22 s$. weekly, for the support of herself and three young children, respectively aged eight, seven, and five, as well as to aid in the maintenance of a crippled daughter of Mr. Brown's by a former wife.

I beg to acknowledge the receipt of a donation of $\$ 5$ from "An Old Patient," sent, since Mr. Brown's death, by Dr. Nichol of Denmark-hill.

I am, Sir, your obedient servant,

Cavendish-square, March 3rd, 1873. Forbes WINSLOW, M.D.

\section{THE CASE OF MR. CROFT.}

\section{To the Editor of The LaNowr.}

Sir,-Will you kindly allow me, through the medium of your valuable columns, to tender my sincere and grateful thanks to the gentlemen who so nobly formed themselves into a committee for the purpose of bringing my very prinful case before my professional brethren and the public, and raising a fund to enable me to meet the very heavy expenses necessarily incurred by my defence. I cannot express how sensibly I feel indebted to those gentlemen who, with the committee, have so handsomely contributed to assist me in my very great distress.

The case came before the Lord Chief Justice Bovill at the Warwick Assizes last week, and upon his lordship's very lucid explanation of the law relating to medical certificates, in his eloquent charge to the Grand Jury, I am thankful to say that both bills, for felony and misdemeanour, which the prosecution filed against me, were at once ignored.

It is my intention to have a number of copies of his lordship's charge struck off, and shall be pleased to forward one to any of my professional bretbren who will apply for one.

Again asking my many kind friends to accept my very grateful thanks through your journal,

I remain, Sir, your very obedient servant,

Snitterfield, March 5th, 1873.

Thos. H. W. Croft.

\section{MEDICAL OFFICERS OF HEALTH AND RURAL SANITARY AUTHORITIES.}

\section{To the Editor of THE LANCET.}

Sir,-I think you must have been pained to notice some of the advertisements which have been lately put forth by various boards of guardians.

If I remember rightly, it was warmly argued by certain members of the House of Commons during the passage of the Public Health Act last year, that it was unfair to cast a doubt on the capabilities of rural boards for the management of their own sanitary affairs, for those who knew them best were sure they would not be found wanting, but would unanimously rise to the occasion, and wield their new powers with wisdom and discretion. If offering skilled and experienced members of our profession the sum of $£ 200$ per annum for superintending an area of nearly 50,000 acres, with a population of over 20,000 (such salary to include all expenses and disbursements), is a step in the right direction, then, indeed, the eyes of the profession must be very widely opened to their own insignificance and want of importance in the public estimation. Such paltry pay as that $I$ have alluded to is positively fixed on a lower scale than that of the long-tried and ill-used union medical officer, who has almost despaired of the good time coming, when he may hope for some alleviation of his lot. I notice that the appointments of medical afficers of bealth " will be subject to the approval of the Local Government Board." If they are asked to approve the man, are they also asked to approve the salary? because, if so, I for one sincerely hope they will take a map in their hands, estimate mileage, travelling expenses, and wear and tear of mind and body, and general responsibility, and then see what sort of equivalent is offered by boards of guardians who are virtually taxing themselves.

\section{I remain, Sir, yours truly,}

A LOOKER-ON ONLT.

P.S. It is evident that the roices of the magistrates (who are ex-officio guardians) are either not raised on behalf of a more liberal policy in framing an organisation for dealing with sanitary questions throughout rural districts, or, if raised, are quickly drowned by their less enlightened and more parsimonious brethren.

\section{PARIS.}

\section{(From our own Correspondent.)}

A $\mathrm{T}$ the last sitting of the Municipal Council, a question of medical interest was brought before the meeting by Dr. Trélat, professor at the School of Medicine and member of the Council. Dr. Trélat presented a report on a demand addressed to the Council by the direction of the Assistance Publique, claiming permission to institute a large laboratory for the purpose of histological investigation at the dissecting amphitheatres of Clamart, which belong to the Administration of the Paris Hospitals. The reporter concluded in favour of the demand, and was supported by all the medical members of the Council (who are very numerous) except Dr. Depaul, who argued that such a laboratory already existed at the School of Medicine. The Council, however, voted the acceptance of the report by a large majority.

It is with great regret I mention the death of $\mathrm{Dr}$. Marchal de Calvi, to whose illness I alluded in my former letter. Dr. Marchal was one of the most brilliant writers in the Paris medical press and though he was very successful as a physician, and had a large practice, he was always an active contributor to the various journals here, from the time he started the Annales de Chirurgie with Velpeau, Bégin, and others, some twenty years ago, almost to the hour of his death, as he was struck by his last attack of illness when returning from the printing office of the Tribune Médicale. He was gifted with most varied and brilliant abilities, and was equally remarkable as an orator and as a writer.

Some elections have recently taken place at the Academy of Medicine. Through the death of the secretary, Fréderic Dubois, Dr. Béclard has been appointed to that important post; also, Dr. Moutard-Martin, physician to Beaujon Hospital, has been elected to the seat which was vacant in the section of Pathology.

Amongst the books brought out last week are the following interesting ones:-De la Névropathie Cérébro-Cardiaque, by Dr. Krischaber (giving the author's observations on a peculiar kind of nervous disorder, which, according to him, had not been described until now); Hystérotomie, by Dr. Péan and M. Urdy (an essay on ablation of the uterus, with an account of Dr. Péan's operations); Des Ruptures Otérines, by Dr. Jolly (in which the symptoms and treatment are especially investigated); Traité de Climatologie Générale $d u$ Globe, by Dr. Armand (an exhaustive treatise by an author of considerable special experience); and last, but assuredly not least, an admirable translation into French of the fifth edition of Dr. John Hughes Bennett's celebrated clinical lectures.

The Municipal Committee entrusted with the ques tion of the Paris water-supply, is now engaged in examining a scheme presented by $M$. Bclgrand, the distin- 